\title{
On-pump inhibition of es-ENT1 nucleoside transporter and adenosine deaminase during aortic crossclamping entraps intracellular adenosine and protects against reperfusion injury: Role of adenosine A1 receptor
}

Anwar Saad Abd-Elfattah, MS, PhD, FAHA, AFSTS, ${ }^{a}$ Mai Ding, MD, ${ }^{\mathrm{b}}$ Michael E. Jessen, MD, FACS, FSTS, FAHA, ${ }^{c}$ and Andrew S. Wechsler, MD, FSTS, FACS ${ }^{\mathrm{d}}$

\begin{abstract}
Objective: The inhibition of adenosine deaminase with erythro-9 (2-hydroxy-3-nonyl)-adenine (EHNA) and the es-ENT1 transporter with p-nitro-benzylthioinosine (NBMPR), entraps myocardial intracellular adenosine during on-pump warm aortic crossclamping, leading to a complete recovery of cardiac function and adenosine triphosphate (ATP) during reperfusion. The differential role of entrapped intracellular and circulating adenosine in EHNA/NBMPR-mediated protection is unknown. Selective (8-cyclopentyl-1,3-dipropyl-xanthine) or nonselective [8-(p-sulfophenyl)theophyline] A1 receptor antagonists were used to block adenosine A1-receptor contribution in EHNA/NBMPR-mediated cardiac recovery.
\end{abstract}

\begin{abstract}
Methods: Anesthetized dogs $(n=45)$, instrumented to measure heart performance using sonomicrometry, were subjected to 30 minutes of warm aortic crossclamping and 60 minutes of reperfusion. Three boluses of the vehicle (series A) or $100 \mu \mathrm{M}$ EHNA and $25 \mu \mathrm{M}$ NBMPR (series B) were infused into the pump at baseline, before ischemia and before reperfusion. 8-Cyclopentyl-1,3-dipropyl-xanthine $(10 \mu \mathrm{M})$ or 8-(p-sulfophenyl)theophyline (100 $\mu \mathrm{M})$ was intra-aortically infused immediately after aortic crossclamping distal to the clamp in series A and series B. The ATP pool and nicotinamide adenine dinucleotide was determined using high-performance liquid chromatography.

Results: Ischemia depleted ATP in all groups by $50 \%$. The adenosine/inosine ratios were more than 10 -fold greater in series B than in series A $(P<.001)$. ATP and function recovered in the EHNA/NBMPR-treated group ( $P<.05$ vs control group). 8-Cyclopentyl-1,3-dipropyl-xanthine and 8-(p-sulfophenyl)theophyline partially reduced cardiac function in series A and B to the same degree but did not abolish the EHNA/NBMPR-mediated protection in series B.
\end{abstract}

Conclusions: In addition to the cardioprotection mediated by activation of the adenosine receptors by extracellular adenosine, EHNA/NBMPR entrapment of intracellular adenosine provided a significant component of myocardial protection despite adenosine A1 receptor blockade. (J Thorac Cardiovasc Surg 2012;144:243-9)

\section{Supplemental material is available online.}

In addition to pre-existing ischemic injury, reperfusion injury has been implicated in poor cardiac recovery despite excellent cardiac repair. ${ }^{1,2}$ Therefore, targeting

\footnotetext{
From the Division of Cardiothoracic Surgery, ${ }^{\text {a }}$ Department of Surgery, Virginia Commonwealth University Medical Center, Richmond, Va; St. Johns Medical Center, ${ }^{\text {b }}$ Longview, Wash; University of Texas South Western, ${ }^{\mathrm{c}}$ Dallas, Tex; and Drexel University Medical Center, ${ }^{\mathrm{d}}$ Philadelphia, $\mathrm{Pa}$.

Supported in part by National Institutes of Health grant R01 HL 05-1090 (to A. S. Abd-Elfattah).

Disclosures: Authors have nothing to disclose with regard to commercial support.

Received for publication June 15, 2011; revisions received Sept 14, 2011; accepted for publication Sept 28, 2011; available ahead of print Feb 9, 2012.

Address for reprints: Anwar Saad Abd-Elfattah, MS, PhD, FAHA, AFSTS, Division of Cardiothoracic Surgery, Department of Surgery, Virginia Commonwealth University Medical Center, 1200 East Broad Street, West Hospital, 7-308 South Wing, Richmond, VA 23298-0068 (E-mail: anwar@vcu.edu).

$0022-5223 / \$ 36.00$

Copyright (C) 2012 by The American Association for Thoracic Surgery

doi:10.1016/j.jtcvs.2011.09.073
}

postischemic reperfusion injury ${ }^{3}$ is critical for improving intra- and postoperative outcomes. Adenosine has emerged as a promising adjuvant agent to augment cardioprotection in experimental models ${ }^{4-6}$ and clinical trials ${ }^{7-10}$ against ischemic and reperfusion injury. Blockade of the adenosine A1 receptor abolishes the cardioprotection mediated by ischemic preconditioning, ${ }^{4}$ and treatment with exogenous adenosine potentiates ischemic preconditioning effects. ${ }^{6}$ Unlike exogenous adenosine, endogenous adenosine generated during ischemia must be transported by way of the p-nitro-benzylthioinosine (NBMPR)-sensitive es-ENT1 transporter 1 (es-ENT1) to the extracellular domain (Figure E1, A) to activate the adenosine receptor subtype (A1, A2A, A2B, and A3)-mediated signaling mechanisms of cardioprotection. Because of the short half life of adenosine in humans and animals, inhibition of adenosine deaminase by erythro-9 (2-hydroxy-3-nonyl)-adenine (EHNA) prolongs its half life and potentiates its pharmacologic efficacy. In addition, selective blockade of es-ENT1 with NBMPR entraps myocardial adenosine and inosine 


\section{Abbreviations and Acronyms \\ ATP = adenosine triphosphate \\ DPCPX $=8$-cyclopentyl-1,3-dipropyl-xanthine \\ EHNA $=$ erythro-9 (2-hydroxy-3-nonyl)- adenine \\ NBMPR $=$ p-nitro-benzylthioinosine \\ SPT $=8$-(p-sulfophenyl)theophyline}

at the site of production during ischemia and prevents its loss during reperfusion. Preischemic treatment with EHNA/NBMPR entraps intracellular adenosine and results in complete recovery of adenosine triphosphate (ATP) and cardiac function, ${ }^{11-13}$ suggesting that the entrapped adenosine is intracellularly compartmentalized (Figure E1, B). The specific binding sites of $\left[{ }^{3} \mathrm{H}\right]$-NBMPR were identified in human and animal myocardial preparations. ${ }^{14}$ The relative contribution of entrapped intracellular adenosine and circulating extracellular adenosine in EHNA/NBMPR-mediated protection in relation to adenosine A1 receptor activation (Figure E1, C) is not known. The present study was designed to determine the role of the adenosine A1 receptor in EHNA/NBMPR-mediated postischemic recovery of function in a canine model of on-pump warm aortic crossclamping (ACC) and reperfusion. Selective blocking of the adenosine A1 receptor with 8-cyclopentyl-1,3-dipropyl-xanthine (DPCPX) or nonselective blocking of adenosine receptor subtypes with 8-(p-sulfophenyl)theophyline (SPT) partially reduces but does not abolish postischemic recovery mediated by EHNA/NBMPR, suggesting intracellular mechanisms of protection.

\section{METHODS \\ Materials}

The biochemical reagents, EHNA and NBMPR, were purchased from Sigma-Aldrich (St. Louis, Mo), and DPCPX and SPT were purchased from Research Biochemical (Natick, Mass).

\section{Animal Model}

The experiments conformed to the Guidelines for the Care and Use of Laboratory Animals published by the US National Institutes of Health (publication no. 5377-3; available at: http://www.nap.edu/catalog/5140. html).

A total of 45 microfilaria-free adult mongrel dogs, of either sex, weighing 17 to $25 \mathrm{~kg}$ were used in the present study. The dogs were initially anesthetized with $35 \mathrm{mg} / \mathrm{kg}$ intravenous sodium pentobarbital (Nembutal; Abbott Laboratories, Chicago, Ill). The surgical procedures and instrumentations were performed exactly as described previously. ${ }^{11}$ Cardiopulmonary bypass was established by subclavian artery and atrial venous cannulation. A membrane oxygenator (Medtronic, Minneapolis, Minn) was used and primed with noncross-matched homologous blood. The mean arterial reperfusion pressure was maintained at 60 to $65 \mathrm{~mm} \mathrm{Hg}$ during bypass. Arterial blood gases, $\mathrm{pH}$, and hematocrit were routinely determined and maintained at the following levels: oxygen partial pressure, 100 to $140 \mathrm{~mm} \mathrm{Hg}$; carbon dioxide partial pressure, 30 to $40 \mathrm{~mm} \mathrm{Hg}$, $\mathrm{pH}, 7.32$ to 7.48 ; and hematocrit, about $30 \%$.

\section{Assessment of Left Ventricular Performance}

Left ventricular (LV) performance was assessed, off the bypass pump, from the relationship between stroke work and the end-diastolic dimension using a sensitive and load-independent index of contractility, ${ }^{11}$ pulse transit sonomicrometry (Triton Technology, San Diego, Calif), and Millar pressure transducers. One pair of lead titanate zirconate piezoelectric hemispheric crystals was sutured to the anterior and posterior of the epicardial surface of the left ventricle wall in the minor axis (40-60 mm). Analog data were digitized at $200 \mathrm{~Hz}$ and stored on a personal computer hard disc and analyzed using interactive Crunch software developed in our laboratory. Data acquisition was performed at varying preloads by way of venous drainage, creating diminishing work loops. The slope was obtained from the relationship between the LV pressures (a surrogate of volume) against the end-diastolic lengths and is considered as a sensitive load-independent index of contractility.

\section{Assessment of Adenine Nucleotide Pool Metabolism}

Transmural serial Tru-Cut needle biopsy specimens $(5-10 \mathrm{mg})$ were obtained and immediately frozen in liquid nitrogen $\left(-196^{\circ} \mathrm{C}\right)$, extracted, analyzed, and quantified using high-performance liquid chromatography, and presented as nmoles/mg protein. ${ }^{11}$

\section{Experimental Protocol}

After a 30-minute stabilization period on pump, the dogs were assigned 1 of 2 series: A or B. Three boluses (500 mL each) of the vehicle solution (saline containing $0.05 \%$ dimethylsulfoxide) without (series A) or with (series B) $25 \mu \mathrm{M}$ NBMPR and $100 \mu \mathrm{M}$ EHNA, were infused into the pump oxygenator before ischemia, before ACC, and just before releasing ACC. The dogs in series A received a single intra-aortic infusion of 50 $\mathrm{mL}$ of saline (control group, $\mathrm{n}=10$ ), $100 \mu \mathrm{M}$ SPT $(\mathrm{n}=6)$ or $10 \mu \mathrm{M}$ DPCPX $(n=7)$ distal to the clamp immediately after ACC. In series B, the dogs were treated with a single intra-aortic infusion of $50 \mathrm{~mL}$ of vehicle (EHNA/NBMPR group, $\mathrm{n}=8), 100 \mu \mathrm{M}$ SPT $(\mathrm{n}=7)$ or $10 \mu \mathrm{M}$ DPCPX $(\mathrm{n}=7)$.

\section{Statistical Analysis}

The data are presented as the mean \pm standard error of the mean. Sequential measurements were compared using repeated measures analysis of variance and Tukey's post hoc tests using SAS (SAS Institute, Cary, NC). Differences were considered significant if the probability value for the comparison of the least squares mean was less than .05 ; the $F$ ratios are provided with the figures.

\section{RESULTS}

The results of the control group and EHNA/NBMPRtreated group have been previously published ${ }^{9,10}$ and are included in the present report for comparison. This model represents a scenario of reversible global myocardial stunning without necrosis, and all dogs survived for the length of the experiments in all groups.

\section{Myocardial ATP}

On-pump normothermic ACC for 30 minutes reduced the myocardial ATP levels by about $50 \%$ in all groups (Figure 1). No recovery of ATP was observed in the series A groups during reperfusion. In series $\mathrm{B}, \mathrm{ATP}$ had recovered at the end of reperfusion in the EHNA/NBMPR-treated 


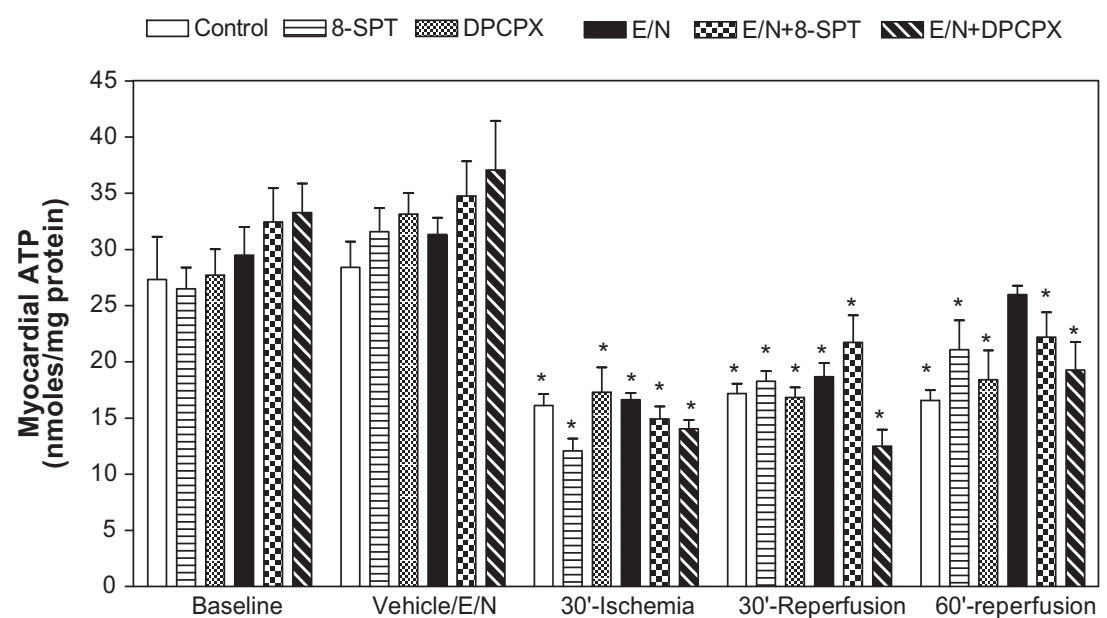

FIGURE 1. Effect of 8-(p-sulfophenyl)theophyline ( $S P T)$ and 8-cyclopentyl-1,3-dipropyl-xanthine (DPCPX) on myocardial adenosine triphosphate (ATP) levels. ATP was measured in myocardial biopsies before and after saline (control) or drug administration and at the end of ischemia and during reperfusion. No significant differences between groups were seen with respect to the time of sampling (analysis of variance, $\mathrm{F}=0.04$ ). *Statistically significant versus baseline. $E / N$, ENHA/NBMPR; ENHA, erythro-9 (2-hydroxy-3-nonyl)-adenine; NBMPR, p-nitro-benzylthioinosine.

group $(25.98 \pm 0.8 \mathrm{nmol} / \mathrm{mg}$ protein vs baseline $28.41 \pm$ $2.3 \mathrm{nmol} / \mathrm{mg}$ protein; $P=\mathrm{NS}$ ). The ATP levels increased in the SPT-treated group in the presence of EHNA/NBMPR to $22.2 \pm 2.2 \mathrm{nmol} / \mathrm{mg}$ protein. ATP remained depressed in the DPCPX groups in both series A and B $(18.4 \pm 2.6$ and $17.30 \pm 2.2 \mathrm{nmol} / \mathrm{mg}$ protein, respectively; $P<.05 \mathrm{vs}$ baseline).

\section{Myocardial Adenine Nucleosides}

Neither adenosine nor inosine was detected before or after EHNA/NBMPR treatment on pump. A small increase in myocardial adenosine occurred at the end of ischemia in the control group $(0.8 \pm 0.1 \mathrm{nmol} / \mathrm{mg}$ protein $)$. Inosine was the major $(>90 \%)$ nucleoside present in the control, SPT-, and DPCPX-treated groups of series $\mathrm{A}$ at the end of ischemia (Figure 2, B). The adenosine and inosine generated during ischemia both disappeared from the myocardium during reperfusion in all groups of series A (Figure 2, A). Myocardial adenosine increased in the EHNA/NBMPR groups (series B) during ischemia as follows: $11.15 \pm 0.7,16.39 \pm 1.6$, and $14.44 \pm 0.9 \mathrm{nmol} / \mathrm{mg}$ protein in the vehicle, SPT, and DPCPX groups, respectively $(P<.05$ vs baseline and series A groups). The inosine levels in the series $\mathrm{B}$ groups were also elevated $(1.40 \pm 0.4,1.49 \pm 0.2$, and $0.55 \pm 0.2$ $\mathrm{nmol} / \mathrm{mg}$ protein at the end of the ischemic period in the presence of vehicle, SPT, and DPCPX, respectively; $P<.05$ vs baseline and series A). During reperfusion, the ischemic myocardium lost all its adenosine and inosine in the series A groups but retained them in the series B groups $(P>.05$ vs baseline and series A groups).

\section{Performance}

Administration of the vehicle solution or EHNA/ NBMPR did not affect LV contractility before ischemia
(Figure 3, A). In series A, LV function in the control group recovered to only $55 \%$ and $71.6 \%$ of preischemic function $\left(44.27 \pm 6.7 \mathrm{dyn} / \mathrm{cm}^{2} \times 10^{3}\right.$ and $57.58 \pm 6.1 \mathrm{dyn} /$ $\mathrm{cm}^{2} \times 10^{3}$ ) after 30 and 60 minutes of reperfusion, respectively (baseline, $80.42 \pm 8.1 \mathrm{dyn} / \mathrm{cm}^{2} \times 10^{3} ; P<.05$ ). SPT significantly reduced cardiac function in series A to less than the control level by $36.7 \%$ and $27.2 \%$ at 30 and 60 minutes of reperfusion, respectively $(P<.05$ vs before ischemia, $\left.75.73 \pm 4.3 \mathrm{dyn} / \mathrm{cm}^{2} \times 10^{3}\right)$. In the presence of DPCPX, LV function had also declined at 30 and 60 minutes of reperfusion to $40.37 \%$ and $43.21 \%$, respectively (before ischemia, $84.65 \pm 8.9 \mathrm{dyn} / \mathrm{cm}^{2} \times 10^{3} ; P<.05$ ). In the EHNA/NBMPR group, the LV function returned to $99.42 \%$ and $119.34 \%$ of the preischemic value after 30 and 60 minutes of reperfusion, respectively (before ischemia, $\left.72.4 \pm 5.9 \mathrm{dyn} / \mathrm{cm}^{2} \times 10^{3} ; P=\mathrm{NS}\right)$. Intraaortic infusion of the nonselective antagonist SPT in the presence of EHNA/NBMPR (series B) resulted in a significant decline in postischemic recovery to $54.03 \%$ and $57.99 \%$ of preischemic function $(39.5 \pm 6.6$ and $42.4 \pm$ $6 \mathrm{dyn} / \mathrm{cm}^{2} \times 10^{3}$ ) after 30 and 60 minutes of reperfusion, respectively (baseline, $73.1 \pm 4.2 \mathrm{dyn} / \mathrm{cm}^{2} \times 10^{3} ; P<.05$ ). DPCPX administration in the EHNA/NBMPR-treated groups resulted in a modest decline in LV functional recovery after global ischemia to $68.23 \%$ and $76.06 \%$ of preischemic function $(54.7 \pm 9$ and $60.9 \pm 7 \mathrm{dyn} /$ $\mathrm{cm}^{2} \times 10^{3}$ ) at 30 and 60 minutes of reperfusion, respectively (baseline, $80.1 \pm 8 \mathrm{dyn} / \mathrm{cm}^{2} \times 10^{3} ; P<.05$ ). When the differences between the percentage of recovery for each corresponding antagonists were plotted for each antagonist in the presence or absence of EHNA/NBMPR (Figure 3,B), it was clear that the reduction in function was identical in series $A$ and $B$ with respect to each antagonist. 

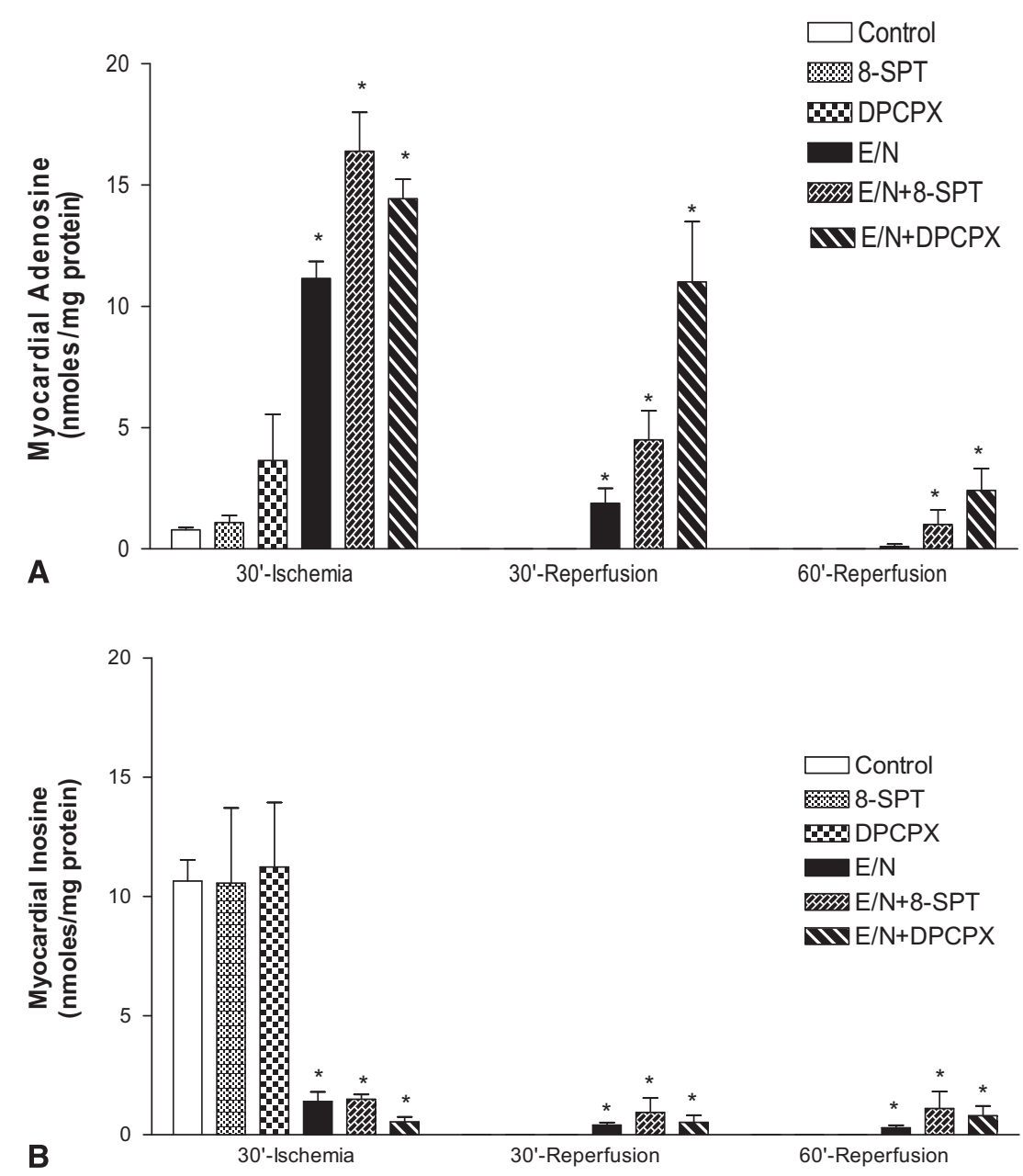

FIGURE 2. Effect of 8-(p-sulfophenyl)theophyline (SPT) and 8-cyclopentyl-1,3-dipropyl-xanthine (DPCPX) on myocardial adenine nucleoside levels. Adenine nucleosides, A, adenosine and B, inosine, were measured in myocardial biopsies before and after saline (control) or drug administration and at the end of ischemia and during reperfusion. Statistically significant differences were found between groups with respect to the time of sampling $(P<.001$, analysis of variance, $\mathrm{F}=11.8$ and $\mathrm{F}=8.8)$. ${ }^{*}$ Statistically significant versus baseline. E/N, ENHA/NBMPR; ENHA, erythro-9 (2-hydroxy3-nonyl)-adenine; NBMPR, p-nitro-benzylthioinosine.

\section{DISCUSSION}

The results from previous studies, ${ }^{11,12}$ also included in the present report, have demonstrated that selective modulation of adenosine deamination with EHNA and transport with NBMPR during ischemia entraps intracellular adenosine and improves postischemic ATP and functional recovery during reperfusion. Because myocardial adenosine was elevated during ischemia more than 10-fold greater in the EHNA/NBMPRtreated groups compared with the controls, it is has been postulated that adenosine receptor subtypes (A1, $\mathrm{A} 2 \mathrm{~A}, \mathrm{~A} 2 \mathrm{~B}, \mathrm{~A} 3)$ are involved in EHNA/NBMPRmediated postischemic recovery. Endogenous adenosinetriggered activation of adenosine receptors is involved in ischemic preconditioning, and DPCPX or SPT abolishes the infarct size limitation mediated by ischemic preconditioning. ${ }^{4-6}$
In the present study, preischemic treatment with EHNA/ NBMPR elevated myocardial adenosine and improved functional and ATP recovery during reperfusion in the absence or presence of adenosine A1 receptor blockade. These results suggest that only a part of the recovery is mediated by extracellular adenosine and activation of membrane surface adenosine receptors. The remaining component of recovery could be mediated by intracellular adenosine and possibly involve intracellular signaling mechanisms of protection. Grube and colleagues ${ }^{15}$ have recently shown evidence for intracellular localization of the A2B adenosine receptor in rat cardiomyocytes.

It has long been assumed that endogenous adenosine, produced during the onset of ischemia, is derived solely from cardiac ATP depletion. This might be true in isolated perfused hearts or cardiomyocytes preparations. Myocardial ischemia triggers sympathetic stimulation and a surge 

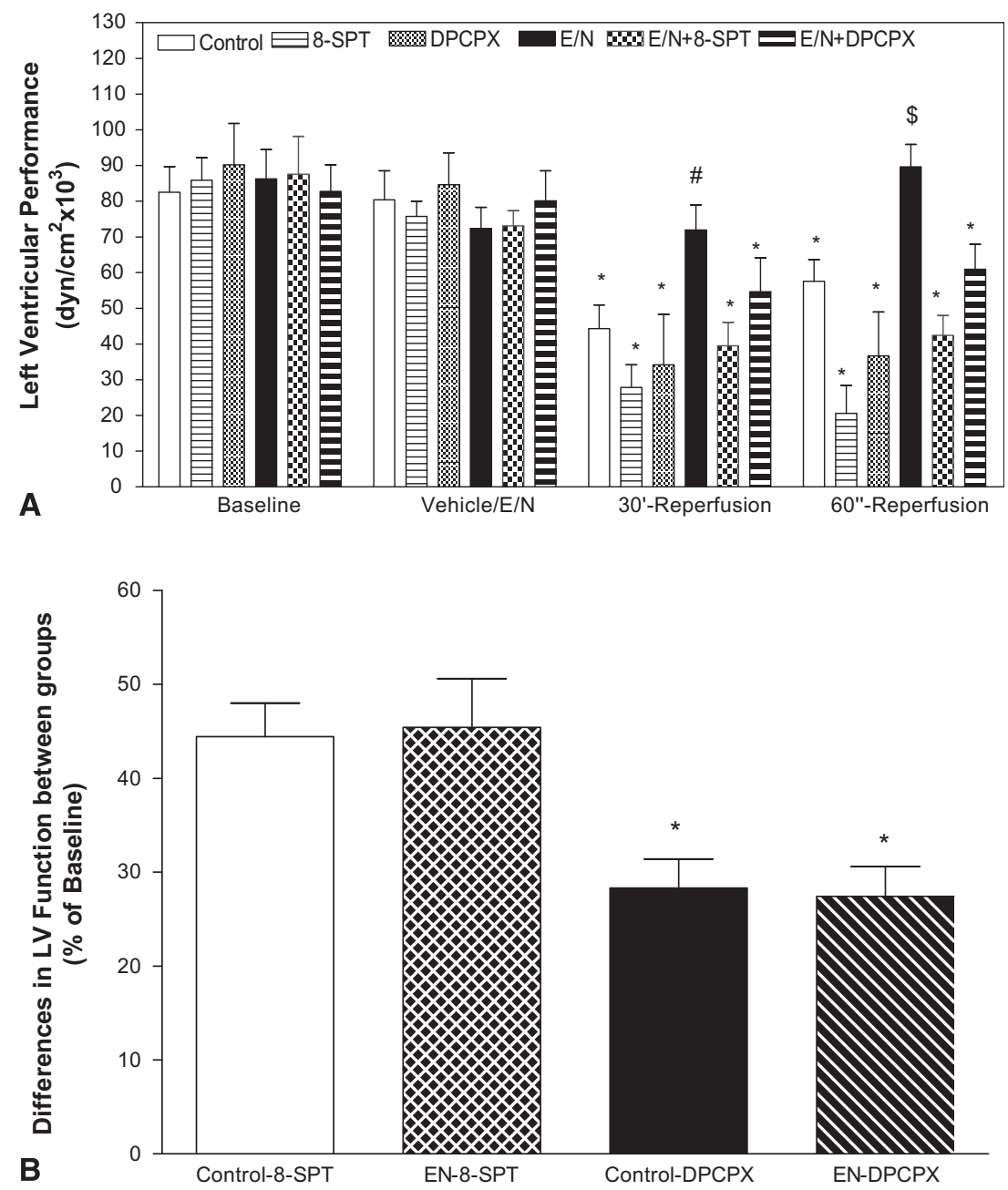

FIGURE 3. Effect of 8-(p-sulfophenyl)theophyline (SPT) and 8-cyclopentyl-1,3-dipropyl-xanthine (DPCPX) on left ventricular ( $L V)$ performance. A, Plot showing the slope of the relationship between the stroke work/end-diastolic dimensions of the left ventricle at each point, except during ischemic arrest. Statistically significant differences seen between groups with respect to the time of sampling $(P<.05$, analysis of variance, $\mathrm{F}=4.18)$. *Statistically significant versus baseline. B, Effect of SPT and DPCPX on the differences between recovery of LV performance. The differences between the percentage of recovery were identical in series A and B, suggesting that the contribution of extracellular adenosine is identical. E/N, ENHA/NBMPR; ENHA, erythro- 9 (2-hydroxy-3-nonyl)-adenine; NBMPR, p-nitro-benzylthioinosine.

of co-released neurotransmitters and ATP. ${ }^{16-18}$ Similar to cardiac adenosine, noncardiac ATP is rapidly broken down in the circulation to adenosine, inosine, hypoxanthine, and xanthine, providing substrates for free radical production catalyzed by xanthine oxidase (Figure E1). It is possible that extracellular adenosine is activating both the DPCPX-sensitive A1 receptor and SPTsensitive $\mathrm{A} 1, \mathrm{~A} 2 \mathrm{~A}, \mathrm{~A} 2 \mathrm{~B}$, and $\mathrm{A} 3$ subtypes. Administration of DPCPX or SPT abolished the contribution only of the surface adenosine A1 receptor and other subtypes in the recovery of function without affecting intracellular adenosine-mediated protection. It has been shown that adenosine receptors cross-talk and work together in concert to induce cardioprotection. ${ }^{19}$ Activation of A2A, A2B, and $\mathrm{A} 3$ is required for $\mathrm{A} 1$ receptor activation. ${ }^{20,21}$ Therefore, we postulate that a DPCPX- or SPT-sensitive contribution in EHNA/NBMPR-mediated recovery is occurring, regardless of the entrapment of intracellular adenosine. The remaining component of functional recovery could be related to unique, yet unknown, intracellular mechanisms of protection.

The adenosine levels were greater in the presence of DPCPX or SPT in the EHNA/NBMPR-treated groups than with EHNA/NBMPR alone (Figure 2, $A$ ). This could be explained, in part, by additive inhibitory effects between EHNA/NBMPR and SPT or DPCPX on adenosine deamination and transport. Despite the greater accumulation of myocardial adenosine in the series B SPT and DPCPX groups, a modest, yet significant, recovery in cardiac function and ATP repletion was observed. Again, postischemic 
repletion of myocardial ATP confirmed that entrapped adenosine is compartmentalized in ischemic cells during ischemia and reperfusion.

The mechanisms of EHNA/NBMPR-mediated augmentation of postischemic recovery could be related to prolonging the half life of intracellular and extracellular adenosine; salvaging intracellular adenosine for ATP, interruption of the formation and the release of inosine as a precursor for the purine-free radical substrates, hypoxanthine and xanthine ${ }^{11}$; and intracellular adenosine activates unknown intracellular signaling mechanisms mediated by intracellular adenosine receptor subtypes. Xia et $\mathrm{al}^{22}$ have reported that inhibition of adenosine deaminase with EHNA (without NBMPR) abolished the formation of free radical species after global ischemia. In an isolated rabbit heart model, EHNA/NBMPR abolished the ischemic preconditioning effects on infarct size. ${ }^{23}$ Infusion of hypoxanthine and xanthine in animals pretreated with EHNA/NBMPR diminished LV function recovery to the control group despite entrapment of intracellular adenosine. ${ }^{11}$ The latter observations implicated the xanthine-oxidase-mediated oxygen free radical generation in postischemic vascular injury "stunning." 24 A cohort study of myocardial protection with specific blockade of the es-ENT1 demonstrated that administration of EHNA/ NBMPR after 20 minutes of warm ACC but before 100 minutes of hypothermic intermittent retrograde coronary sinus cardioplegia abolished myocardial stunning, regardless of cardioplegic arrest and reperfusion (unpublished data). Our results have provided evidence that, in addition to adenosine/adenosine receptor protective mechanisms, entrapment of adenosine and inosine provides alternative (or rather additive, if combined) cardioprotection that might contribute to functional recovery. Our findings should be considered in future clinical trials of adenosine and adenosine-modulating agents to reduce the dosage and augment pharmacologic efficacy. The present results support the concept that nucleoside entrapping is effective in attenuating postischemic reperfusion injury in a severe scenario of warm global ischemia. It is anticipated that this intervention would be more efficacious under intraoperative procedures of myocardial protection. This modality has important clinical potential to improve the clinical outcomes of off- or on-pump cardiac surgery, especially in sicker and elderly patients with low metabolic and contractile reserves.

\section{Study Limitations}

The present study had obvious experimental model limitations that must be considered, including species-, age-, and model-related differences.

The issue of the species-dependent presence of xanthine oxidase remains debatable. However, it is believed that the porcine heart resembles the human anatomy and coronary distribution. The doses of EHNA and NBMPR were used according to our previous reports, ${ }^{3,4}$ which were greater than the $\mathrm{K}_{\mathrm{i}}$ values $(0.05 \mathrm{nM})$. The dose-response relationship was not intended in the present canine model of ACC. The timing of the administration of vehicle and EHNA/NBMPR was considered to target specific modulation of adenosine metabolism and compartmentalization during global warm ischemia and reperfusion.

\section{CONCLUSIONS}

In addition to the adenosine A1 receptor- and other subtype-mediated protective mechanisms by extracellular adenosine, selective entrapment of intracellular adenosine significantly improved postischemic functional and ATP recovery after severe warm global ischemia. Modulation of the adenosine metabolism and compartmentalization could serve as an important new modality to improve intraoperative recovery of stunned hearts and attenuate acute reperfusion injury in the settings of thrombolytic therapy, percutaneous coronary intervention, coronary artery bypass grafting, and resuscitation from hemorrhagic or cardiogenic shock.

\section{References}

1. Braunwald E, Kloner RA. Myocardial reperfusion: a double-edged sword? J Clin Invest. 1985;76:1713-9.

2. Mangano DT, Miao Y, Tudor IC, Dietzel C, Investigators of the Multicenter Study of Perioperative Ischemia (McSPI) Research Group; Ischemia Research and Education Foundation (IREF). Post-reperfusion myocardial infarction: long-term survival improvement using adenosine regulation with acadesine. J Am Coll Cardiol. 2006;48:206-14.

3. Abd-Elfattah A, Higgins R, Latifi R, Merrell R. Targeting post-ischemic reperfusion injury: scientific dream and clinical reality. New Surg. 2001;1:41-51.

4. Liu GS, Thornton J, Van Winkle DM, Stanley AW, Olsson RA, Downey JM. Protection against infarction afforded by preconditioning is mediated by A1 adenosine receptors in rabbit heart. Circulation. 1991;84:350-6.

5. Schultz R, Rose J, Post H, Heusch G. Involvement of endogenous adenosine in ischemic preconditioning in swine. Pflugers Arch. 1995;430:273-82.

6. McCully JD, Uematsu M, Parker RA, Levitsky S. Adenosine-enhanced ischemic preconditioning provides enhanced postischemic recovery and limitation of infarct size in the rabbit heart. J Thorac Cardiovasc Surg. 1998;116:154-62.

7. Mentzer RM Jr, Rahko PS, Molina-Viamonte V, Canver CC, Chopra PS, Love RB, Cook TD, Hegge JO, Lasley RD. Safety, tolerance, and efficacy of adenosine as an additive to blood cardioplegia in humans during coronary artery bypass surgery. Am J Cardiol. 1997;79(12A):38-43.

8. Mentzer RM Jr, Birjiniuk V, Khuri S, Lowe JE, Rahko PS, Weisel RD, et al. Adenosine myocardial protection: preliminary results of a phase II clinical trial. Ann Surg. 1999;229:643-9.

9. Kloner RA, Forman MB, Gibbons RJ, Ross AM, Alexander RW, Stone GW. Impact of time to therapy and reperfusion modality on the efficacy of adenosine in acute myocardial infarction: the AMISTAD-2 trial. Eur Heart J. 2006;27: 2400-5.

10. Ross AM, Gibbons RJ, Stone GW, Kloner RA, Alexander RW, AMISTAD-II Investigators. A randomized, double-blinded, placebo-controlled multicenter trial of adenosine as an adjunct to reperfusion in the treatment of acute myocardial infarction (AMISTAD-II). J Am Coll Cardiol. 2005;45:1775-80.

11. Abd-Elfattah AS, Jessen ME, Lekven J, Doherty NE III, Brunsting LA, Wechsler AS. Myocardial reperfusion injury: role of myocardial hypoxanthine and xanthine in free radical-mediated reperfusion injury. Circulation. 1988; 78(5 Pt 2):III224-35.

12. Abd-Elfattah AS, Jessen ME, Lekven J, Wechsler AS. Differential cardioprotection with selective inhibitors of adenosine metabolism and transport: role of purine release in ischemic and reperfusion injury. Mol Cell Biochem. 1998;180: 179-91

13. Abd-Elfattah AS, Ding M, Wechsler AS. Intermittent aortic cross clamping prevents cumulative adenosine triphosphate depletion, ventricular fibrillation, and 
dysfunction (stunning): is it preconditioning? J Thorac Cardiovasc Surg. 1995; 110:328-39.

14. Abd-Elfattah AS, Hoehner J, Wechsler AS. Identification of nucleoside transport binding sites in the human myocardium. Mol Cell Biochem. 1998;180:105-10.

15. Grube K, Rüdebusch J, Xu Z, Böckenholt T, Methner C, Müller T, et al. Evidence for an intracellular localization of the adenosine A2B receptor in rat cardiomyocytes. Basic Res Cardiol. 2011;106:385-96.

16. Dobson JG Jr, Schrader J. Role of extracellular and intracellular adenosine in the attenuation of catecholamine evoked responses in guinea pig heart. $J$ Mol Cell Cardiol. 1984;16:813-22.

17. Poelchen W, Sieler D, Wirkner K, Illes P. Co-transmitter function of ATP in central catecholaminergic neurons of the rat. Neuroscience. 2001;102:593-602.

18. Burnstock G. Purine cotransmission. Exp Physiol. 2009;94:20-4.

19. Xi J, McIntosh R, Shen X, Lee S, Chanoit G, Criswell H, et al. Adenosine A2A and $\mathrm{A} 2 \mathrm{~B}$ receptors work in concert to induce a strong protection against reperfusion injury in rat hearts. J Mol Cell Cardiol. 2009;47:684-90.
20. Urmaliya VB, Pouton CW, Ledent C, Short JL, White PJ. Cooperative cardioprotection through adenosine $\mathrm{A} 1$ and $\mathrm{A} 2 \mathrm{~A}$ receptor agonism in ischemia-reperfused isolated mouse heart. J Cardiovasc Pharmacol. 2010;56:379-88.

21. Zhan E, McIntosh VJ, Lasley RD. Adenosine A2A and A2B receptors are both required for adenosine A1 receptor-mediated cardioprotection. Am J Physiol Heart Circ Physiol. 2011;301:H1183-9.

22. Xia Y, Khatchikian G, Zweier JL. Adenosine deaminase inhibition prevents free radical mediated injury in the postischemic heart. J Biol Chem. 1996;271: 10096-102.

23. Walsh RS, Abd-Elfattah AS, Daly JJF, Wechsler AS, Downey J. Selective blockade of nucleoside transport channels prevents preconditioning of rabbit myocardium. Surg Forum. 1993;XLIV:234-6.

24. Zughaib ME, Abd-Elfattah AS, Jeroudi MO, Sun JZ, Sekili S, Tang XL, et al Augmentation of endogenous adenosine attenuates myocardial "stunning" independently of coronary flow or hemodynamic effects. Circulation. 1993;88(5 Pt 1):2359-69. 

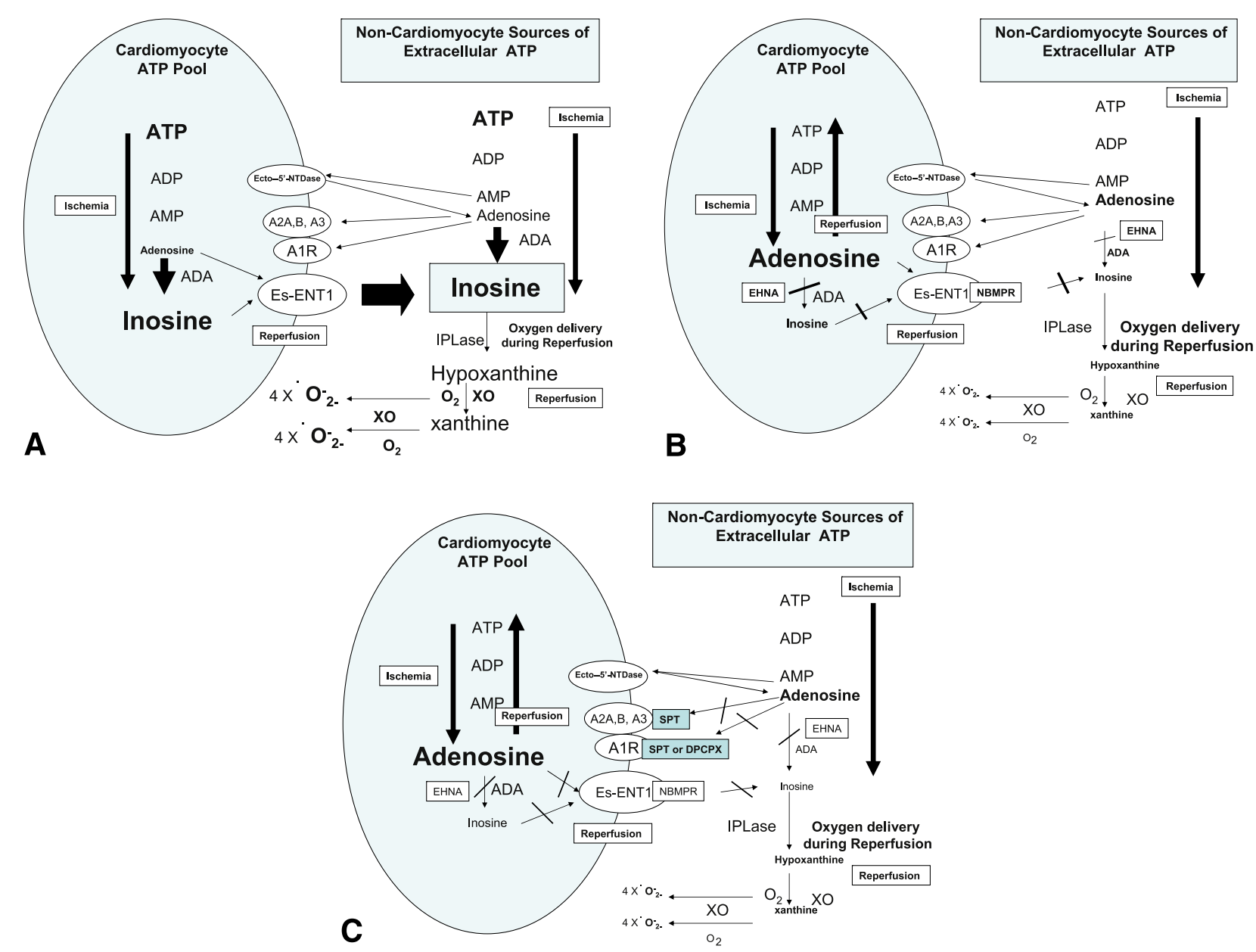

FIGURE E1. Adenosine triphosphate (ATP) and purine metabolism during ischemia and reperfusion. Massive ATP depletion occurs at the onset of myocardial ischemia. The es-NT1 nucleoside transporter allows the release of both adenosine and inosine on reperfusion more effectively than during ischemia. On reperfusion, nucleosides are released and converted to hypoxanthine and xanthine, both substrates of xanthine oxidase and free radical production ${ }^{3}$ and oxidized to free radicals. A, Noncardiac ATP co-released from nerve endings with neurotransmitters is also degraded by ecto (external active site)-ATPases, ecto-nucleotidases, and adenosine deaminae, elevating the levels of extracellular adenosine and inosine, leading to activation of adenosine A1 receptormediated signaling mechanisms. B, Erythro-9 (2-hydroxy-3-nonyl)-adenine (EHNA)/p-nitro-benzylthioinosine (NBMPR) inhibits intracellular and extracellular adenosine deaminase activity and blocks es-NT1 transport system, allowing intracellular accumulation of mainly adenosine during ischemia and reperfusion, limiting hypoxanthine and xanthine formation and free radical production. C, Administration of selective or nonselective adenosine receptor antagonists blocked the action of extracellular adenosine but not the action of intracellular adenosine, interrupting adenosine receptor-mediated signaling mechanisms. ADP, Adenosine diphosphate; AMP, adenosine monophosphate; ADA, adenosine deaminase; A1R, adenosine A1 receptor; IPLase, inosine phosphorylase; es-ENT1, es-ENT1 transporter 1. 